\author{
THIS MANUSCRIPT IS UNDER REVIEW AT INTEGRATIVE CANCER THERAPIES \\ FOR PROPER CITATION AND FINAL CONTENT PLEASE CHECK: \\ https://journals.sagepub.com/home/ict
}

\title{
Factors underlying the use of non-conventional medicine and forgoing biomedical treatment among patients with cancer - Recommendations for doctor-patient communication
}

Short title: Forgoing biomedical treatment among patients with cancer - Recommendations for doctorpatient communication

Authors:

Szilvia Zörgő, Semmelweis University, Budapest, Hungary

Samvel Mkhitaryan, Maastricht University, Maastricht, Netherlands

Funding:

No funding was received for developing the content of this article.

Declaration of Conflicting Interests:

The authors declare that there is no conflict of interest.

\section{Abstract:}

The use of Complementary and Alternative Medicine (CAM) is increasing and a considerable number of patients forgo biomedicine, employing these non-conventional modalities as an alternative to orthodox cancer treatment. CAM use and motivations vary according to how and to what ends it is being used. Values, such as a preference for "natural" cures and lay theories of illness causation play a pivotal role in choice of therapy. These, in turn, affect and are affected by the manner in which the patient encounters and interprets information. CAM use may signify a point of tension in the doctor-patient relationship, as both parties are frequently reluctant to discuss the issue, albeit non-conventional modalities may pose threats to patient safety and thus warrant open communication. Extensive research in this particular area of medical communication is scarce, even more so concerning patients who forgo biomedical treatment completely. The following contains practical recommendations for communicating with patients at risk of declining conventional cancer treatment. 


\section{INTRODUCTION}

The use of non-conventional diagnostic and treatment methods, that is, Complementary and Alternative Medicine (CAM), is increasing throughout the Western world ${ }^{1}$. Studies suggest CAM use is highest among middle-aged, wealthy, well-educated, Caucasian females suffering from breast cancer ${ }^{1-5}$. Reasons for using CAM in cancer include aiming to cure or inhibit the exacerbation of the disease and alleviating side-effects of conventional treatment ${ }^{6}$. Non-conventional modalities can be employed in conjunction with biomedicine (complementary treatment) or instead of it (alternative treatment); the latter implies forgoing conventional cancer treatment. Albeit most patients consider non-conventional approaches as augmenting therapies, a growing number of individuals employ CAM to the exclusion of biomedicine. After a brief overview of the definition and prevalence of CAM, the following narrative review discusses motivations underlying the use of CAM modalities in cancer and factors behind forgoing conventional treatment. Finally, some specific recommendations for doctor-patient communication are disclosed and contextualized within the relevant literature.

\section{Defining Complementary and Alternative Medicine (CAM)}

CAM is most frequently defined as "non-conventional medicine": modalities that do not comprise part of conventional medicine in a given country's healthcare system. Yet, for the purposes of research and well-rounded understanding, it does not suffice to rely on just this. What is considered "conventional" can differ greatly depending on specific attributes of a healthcare system, as well as cultural, socioeconomic, and political factors. In a definition developed for the Cochrane Collaboration, CAM is described as "A broad domain of healing resources that encompasses all health systems, modalities, and practices and their 
accompanying theories and beliefs, other than those intrinsic to the politically dominant health systems of a particular society or culture in a given historical period" ${ }^{7}$. This directs attention to the fact that CAM modalities are usually not only a product or service, but are embedded in a larger cultural system with specific values and practices. Furthermore, it is implied in the definition, that biomedicine is not always the dominant medical system of a country; in fact, according to 2005 WHO data, $80 \%$ of the world population relies on traditional, folk remedies as their primary source of healthcare ${ }^{8}$.

\section{Prevalence in CAM use}

Meta-analyses on the prevalence of CAM use are rare because such figures are not easily comparable on an international scale. A systematic review from 2012 revealed that the 12-month prevalence of CAM use in the general population varied from $9.8-76 \%^{1}$. The high variance in the available prevalence estimates of CAM use limits the scope of conclusions that can be drawn. The variability of this is due to e.g. differing operationalizations, recall bias, and insufficient representation of countries in the study samples ${ }^{9}$. For example, making the distinction between complementary and alternative CAM use in operationalization is an important one, not only in terms of prevalence but also regarding patient motivations underlying its use. Non-conventional medicine is most frequently employed in tandem with biomedicine; while alternative use is less common, but still high, as this figure may reach $30 \%$ of all CAM users $^{3,10}$.

The majority of CAM users (69.4\%) seem to exhibit a preference for one CAM modality, although employing several modalities is not uncommon either ${ }^{9}$. Those who select spiritual healing and acupressure are more frequently reported to be alternative users compared to other CAM modalities ( $14.9 \%$ and $12.1 \%$ 
respectively) ${ }^{9}$. CAM is most commonly used to treat chronic diseases and its usage is high among cancer patients ${ }^{9,11}$. A systematic review and a meta-analysis revealed that CAM use among cancer patients has increased from an estimated $25 \%$ in the 1970 s and 1980 s to $49 \%$ after $2000^{12}$, particularly among those with breast cancer (prevalence rate $\geq 40 \%)^{13-17}$. Cancer patients in Europe seem to have higher odds of referring to mind-body practices compared to those with no health problems ${ }^{9}$. CAM use among cancer survivors is significantly higher than among cancer patients $(66.5 \%$, of which $43.3 \%$ employed CAM during the past year) ${ }^{18}$.

\section{COMPLEXITY IN HOW CAM IS EMPLOYED}

Understanding motivations underlying CAM use requires a level of complexity that accounts for differences in complementary versus alternative use vis-à-vis the specific illness and its clinical characteristics. For example, Astin showed that dissatisfaction and distrust in biomedicine (as a whole or with a specific provider) was a significant predictor of the alternative, but not the complementary use of non-conventional medicine. In alternative use, psychological constructs such as holistic thinking and spirituality were predictive ${ }^{10}$, although the few other studies examining this show varying results ${ }^{19}$. Furthermore, attitudes and behavior might differ a great deal, as there are a number of patients who would prefer to avoid pharmaceuticals, but due to their condition, are forced to adhere to conventional treatment. The illness in question is also essential to consider, e.g.: using acupuncture as an alternative to biomedicine in treating migraines or tendinitis is a different issue than treating appendicitis or cancer with solely acupuncture. Additionally, decision-making is time-sensitive and context-dependent ${ }^{20}$; strategies may differ 
in various stages of one particular illness or at the onset of a new symptom. Also, decisions (as well as their subsequent appraisal) regarding comorbidities may have a strong influence on each other ${ }^{10}$.

Some authors argue that CAM users should be differentiated based on their level of commitment to CAM use, which is strongly associated with how much they identify with the sociocultural and behavioral environment of the CAM modality ${ }^{21}$. Others would group CAM users based on their underlying motivations into the following three categories: CAM use stemming from worldview (principle-based), stemming from dissatisfaction with conventional medicine (frustration-based), and those just "shopping around" or using CAM out of curiosity (opportunist use) ${ }^{22}$. Making such distinctions can be a useful analytic tool, while keeping in mind that these typological lines may be blurred and categories may overlap (e.g. opportunist use may frequently be prompted by some kind of dissatisfaction).

\section{FACTORS UNDERLYING CAM USE}

Patient motivations in CAM use are addressed by several hypotheses. The market niche hypothesis asserts that CAM appeals to patients in areas where biomedicine is perceived to be lacking: patient-centered care and the attribution of meaning to suffering ${ }^{23-25}$. Boon et al. take another approach by grouping aspects into "fixed decision factors" that the patient cannot change (e.g. demographic characteristics, comorbid conditions, disease status) and "flexible decision factors" (e.g. patient perceptions of conventional and CAM treatments, psychological needs) ${ }^{26}$. The Push and Pull dichotomy states factors can be grouped into the categories of "push factors" repelling patients from biomedicine (e.g. ineffective cure for their illness or severe side-effects) and "pull factors" drawing patients toward CAM ${ }^{27}$. The most prominent pull factor is "philosophical congruence" ${ }^{28}$, which occurs when a patient believes they have identified their own cultural 
values in the sociocultural environment of a CAM modality. As CAM is often embedded in a distinct worldview, such congruence may occur in a wide variety of ways with an assorted constellation of values and attitudes.

According to a number of studies, the effects of values or beliefs eclipse patient dissatisfaction in motivations underlying CAM use ${ }^{1,2,10,29}$. Values that have been linked to increased CAM use include a preference for more control and empowerment in the illness experience $2,24,30,31$ and in the practitionerpatient relationship ${ }^{2,32,33}$, as well as a marked need for social support ${ }^{3,32}$.

Many studies explore the correlations among CAM use and psychological constructs such as positive thinking ${ }^{2}$, optimism ${ }^{34,35}$, self-efficacy and agency ${ }^{36,37}$, as well as holistic thinking ${ }^{38,39}$. Yet such constructs differ in how they are defined and measured, suggesting that studies' use of identical construct labels does not necessarily imply that they are measuring the same phenomenon ${ }^{40}$. Thus, explaining CAM use in this manner may not provide the most accurate picture of patient motivations.

CAM has also been examined in correlation with Modern Health Worries (MHW) ${ }^{41}$, beliefs concerning the perceived detrimental effects on health posed by modern, technological advances and devices, as well as urbanization. Items in the scale relate to environmental pollution, toxic interventions, radiation, and food additives. CAM use exhibits a positive correlation with $\mathrm{MHW}^{42}$, as well as Medical Conspiracy Theories ${ }^{43}$ and somatosensory amplification ${ }^{44}$.

International studies have found that CAM users tend to retain a preference for the "natural", often defined as "clean", "healthy", and "not man-made" 36,45,46. The "natural" may also be linked to dietary choices, such as consuming "organic" and "unprocessed" food that does not contain "toxins" or additives. Natural therapies are conceptualized as harmless and drawing on the body's "self-healing" mechanisms; 
these therapies are usually equated with herbal, folk or traditional medicine ${ }^{47}$. With a preference for the natural in mind, pharmaceuticals may be seen as "chemicals" to be avoided ${ }^{45,48}$.

A widespread etiology among CAM users is the accumulation of "toxins" or "chemicals" in the body, which is conceptualized as an inevitable part of modern, urbanized life ${ }^{45}$. In fact, 15 out of 24 studies discussed in a systematic review of lay etiologies in breast cancer found that patients believed there was a connection between exposure to environmental toxins and their diagnosis ${ }^{49}$. A practice congruent with this etiology is "detoxification" via various diets and cleansing processes with the aim of regaining health and boosting the immune system. Siahpush argues that these attitudes may have a metaphoric element as well: if the body is seen as "part of nature", it can be "polluted" similarly to environmental pollution ${ }^{29}$.

Several studies have found that the use of "natural products", like vitamins and herbs, is prevalent among cancer patients ( for example, $64-81 \%$ in the USA ${ }^{50}, 32 \%$ in Japan ${ }^{51}, 43 \%$ in Germany ${ }^{52}$ ). Qualitative studies, such as Arthur et al.'s conducted with 23 cancer patients ${ }^{2}$, emphasize lay associations between the "natural" and the "benign", other studies highlight connections to perceived safety 53 . Chemotherapy and radiation therapy, on the other hand, are frequently seen by cancer patients as "toxic" and hazardous ${ }^{2,54}$. Again, it is worthwhile noting that the construct of "natural" may differ among studies, some may only consider herbal products to be natural, while others also include e.g. massage and relaxation in this category.

Furthermore, studies have shown that lay psychosocial etiologies are strong predictors of CAM use 32,38 , which implies that the patient adheres to a (largely) unidirectional causality between "soul" or "mind" and body. In this worldview, psychosocial phenomena are believed to cause somatic illnesses, and congruently, healing is also accredited to psychological changes ${ }^{29,47,55}$. Psychologization is dominant in the 
broader healthcare market of Western countries with many patients conceptualizing healing as the transformation of the Self through illness or "personal growth" $25,36,37,56,57$. Consequently, this etiology may cause the patient to see pharmaceuticals and biomedical procedures as inadequate treatment for somatic ailments that are "in reality" caused by psychosocial problems ${ }^{25,47}$.

A substantial portion of cancer patients attribute their illness to psychosocial factors. A systematic review on breast cancer patients reports that in 21 out of 24 studies psychosocial factors were among the most popular attributions ${ }^{49}$. Studies conducted with, for example, cervical cancer ${ }^{58}$ and lung cancer patients ${ }^{59}$ also confirm this, but attributions may differ widely based on sociodemographic and clinical variables. Furthermore, beliefs regarding the meaning or causality of illness may change in an individual over time. Additionally, a large number of cancer patients view their disease as a punishment for their own shortcomings, failings. Many studies investigate the adaptiveness of self-blame with ambiguous results, as self-blame can be adaptive via re-establishing the patient's belief in a controllable environment, but it can also be maladaptive, leading to feelings of guilt, anxiety, depressive states, and increased self-stigmatization 49,59 .

\section{DYSFUnCtional CAM USE}

Thus, for analytic purposes, CAM can be seen as embedded in a larger cultural system and retaining a sociocultural environment with specific values and practices. Non-conventional modalities may be employed in tandem with biomedicine as a complementary therapy, but can also serve as alternative treatments. The decision to employ non-conventional medicine is generally recursive in the patient journey, and it is time and context dependent. Although the complementary use of CAM is more common, patients may often 
employ non-conventional medicine to the exclusion of biomedicine. Alternative use does not always pose a threat to patient safety, and its frequency is well illustrated by the fact that patients regularly attempt to treat most of their complaints and mild illnesses with home remedies or some form of self-healing ${ }^{60}$. Yet if patients refuse to undergo or elect to discontinue conventional therapy when faced with life-threatening disease, the exclusive use of CAM endangers the individual and can be referred to as "dysfunctional CAM use" 61 .

Patients with cancer may employ CAM as a complementary therapy to inhibit the exacerbation of the disease, alleviate side-effects of conventional treatment, boost their immune system, gain a sense of control in their therapeutic process or experience increased social support through the sociocultural environment of a CAM modality ${ }^{6,32}$. Acting in accordance with a preference for "natural cures" or a lay theory of illness causation (e.g. attributing cancer development to psychosocial factors) may lead the patient to forgo conventional therapy if they see therapeutic choices as mutually exclusive. The decision to employ CAM (and in what way) depends on a myriad of factors, such as the ones discussed above. Another vital element in the decision-making process is the relationship between the cancer patient and their treating physician(s), which is crucially determined by doctor-patient communication. Communication is especially important if the cancer patient is at risk of declining conventional therapy; furthermore, poor communication can greatly contribute to their decision to forgo treatment ${ }^{47,62}$. Despite its pivotal importance, extensive research in this particular area of medical communication is scarce. Authors such as Frenkel et al. ${ }^{63,64}$, Verhoef \& White ${ }^{20,62}$, Winslow \& Shapiro ${ }^{65}$, Ge et al. ${ }^{66}$, Tenner et al. ${ }^{67}$ and Zörgő \& Olivas ${ }^{47}$ have outlined specific recommendations based on empirical research. These are detailed below and contextualized within relevant literature. 


\section{RECOMMENDATIONS FOR DOCTOR-PATIENT COMMUNICATION}

\section{Talking about conventional therapy}

Leave time after diagnosis

At the point of diagnosis, the patient is "run-over", overwhelmed by information; as Koehler et al. put it: "the patient's identity as a whole is altered by the global loss of their former references and orientation points" ${ }^{\prime 68}$. The experience of hearing a diagnosis can denote a mental traumatization that requires emotional and intellectual processing. In their qualitative study with 31 cancer patients refusing one or more conventional therapy, Verhoef \& White detail the accounts of patients being offered treatments "closely intertwined with the shock of diagnosis", leading them to feel pressured into immediately complying with the conventional therapy ${ }^{62}$. There is evidence to suggest that the prospective assessment of a treatment, through anticipatory mechanisms and expectancy, can affect the experience of the therapy and its sideeffects: low preference for a treatment mid-intervention can be associated with a lower quality of life, as well as worse nausea/vomiting and cancer symptoms ${ }^{69,70}$. Thus, if a patient feels pressured into complying with a therapy, it may negatively influence future adherence, side-effect intensity, and treatment experience.

Do not employ "scare tactics"

Appeals to fear, messages aimed at changing behavior by creating anxiety, are widely used in health communication and public health initiatives. Yet, an article investigating 60 years of fear appeal research concludes that experimental evidence argues against the use of threatening health information ${ }^{71}$. The 
patient perspective seems to correlate with this: using "scare tactics", such as "If you don't accept this therapy, you will be dead within a year", tends to invoke resentment and diminishes trust in the doctorpatient relationship ${ }^{62}$.

Be clear about side-effects

Side-effects exerting a negative impact on the patient's physical, social, or emotional functioning may lead the patient to discontinue their therapy ${ }^{72}$. In a qualitative study, Zörgő \& Olivas found that patients often terminated their radiation or chemotherapy because they experienced novel somatic sensations, which they either felt could not report to their doctor (due to the perceived nature of the doctor-patient relationship) or tried to report them but were unable to (dismissed by the doctor as a moot topic). The authors also describe how patients who are asymptomatic at the onset of treatment may experience side-effects for the first time and interpret the sensations as therapeutic inefficacy or iatrogenic effect ${ }^{47}$. It is hence crucial to maintain a discussion about (both expected and unexpected) side-effects throughout the therapeutic process.

\section{Talking about CAM}

(Non-)disclosure of CAM use

Patients using CAM frequently do not inform their physician about the employed complementary therapy. Prevalence of non-disclosure varies greatly depending on country, illness, and prognosis, but studies indicate that $40-77 \%$ of CAM users keep this information from their treating physician ${ }^{4,73-76}$. According to a metaanalysis, CAM use in cancer ranged between $11-95 \%$, while $20-77 \%$ of patients did not inform their physician 
about the employed modalities ${ }^{77}$, even though studies suggest physicians retain a strong interest in knowing whether their patient is using non-conventional approaches ${ }^{65,78}$. Fostering a mere desire to talk about CAM may not suffice: for example, one study conducted with over 300 physicians in the USA found that although $84 \%$ wanted to know more about CAM, only $8 \%$ asked their patients about their CAM use, $17 \%$ never asked, while $52 \%$ asked their patients less than half of the time ${ }^{65}$.

\section{Initiate the conversation}

From the patient's point of view, the prevailing reason behind non-disclosure is that they are afraid of the physician's reaction, their condemnation, or the patient believes the doctor is indifferent to their use of CAM. Other justifications of non-disclosure include: the doctor did not inquire about it, there was insufficient time to discuss it, or the physician would be incompetent in the subject $4,37,47,75,77,79$. Whether the patient initiates or participates in such conversations depends on a variety of factors including: the level of trust in the doctor-patient relationship, effective communication strategies, societal and subcultural appraisal of the employed CAM modality, relationship between biomedicine and CAM in the particular healthcare system ${ }^{80}$. Due to the fact that so many factors determine whether a patient discloses their CAM use or not, it is advised that the physician initiates the conversation and sporadically returns to this issue throughout the treatment trajectory.

Failing to discuss CAM use can pose dangers to patient safety through complementary substances adversely interacting with or hindering the efficacy of conventional treatment. Another issue is exemplified via a study conducted by Adler among breast cancer patients, $72 \%$ of whom employed a CAM modality. Only $54 \%$ of CAM users informed their treating physician about the non-conventional approaches, yet $94 \%$ 
regularly discussed their conventional therapy and test results with their CAM practitioner ${ }^{81}$. This directs attention to the importance of establishing and cultivating trust in the doctor-patient relationship in order to maintain an unhindered flow of crucial health-related information and increase patient safety.

\section{Ask about reasons for declining treatment}

If the patient divulges that they are considering declining the conventional therapy, delving deeper into their rationale can be useful. The mere act of asking to know more about the patient's decision-making process and practicing active listening strengthens the therapeutic bond ${ }^{82}$. At this point, there is no need to agree or disagree with what the patient discloses. Active listening (listening and expressing attentiveness in a verbal and/or non-verbal manner) and the expression of empathy are essential in good communication, which in

turn, translates into better adherence ${ }^{83-85}$. Opening a discussion about the advantages and disadvantages of each therapeutic option is also an excellent way to explore the patient's underlying preferences, assumptions, and fears.

\section{Do not condemn the patient's decisions}

According to cognitive dissonance theory, people select information congruent with their existing beliefs, because incongruence (i.e. dissonance) can lead to significant mental and physical discomfort ${ }^{86,87}$. The information physicians provide the patient concerning both conventional and non-conventional therapies may be in dissonance with the knowledge and beliefs the patient already holds. Even from a trusted source, novel information aimed to change beliefs or behavior may achieve the exact opposite to its intention: it 
may strengthen existing beliefs; this is referred to as the backfire (aka the boomerang effect) ${ }^{88-91}$. This has been well-observed with e.g. political convictions ${ }^{92}$, conspiracy theories ${ }^{93}$, and vaccine hesitancy ${ }^{94}$.

In a situation where the physician retains a negative opinion on CAM and the patient is considering the exclusive use of non-conventional medicine, if the former states their opinion upfront, it may achieve pushing the patient more towards dysfunctional CAM use. CAM modalities serve certain psychological (e.g.: agency, social support) and physical needs (e.g.: side-effect alleviation, pain management), which the patient may feel are vital for their quality of life and survival. As discussed earlier, CAM use is frequently congruent with existing beliefs and attitudes; depending on the intensity with which the individual identifies with CAM, and (inadvertently) directing a negative comment at a stronghold of consonance may be interpreted by the patient as the physician "rejecting" them personally ${ }^{47}$. Thus, it is advised to take on a dialogic, rather than a didactic stance when talking about non-conventional medicine. Furthermore, such a dialogic approach may assist the conventional treatment by revealing clinically relevant information about side-effects, decreasing the chances of the patient employing therapies that interact negatively, and building rapport.

\section{Offer counseling}

Lay theories of illness causation and consequent therapy choice are influenced greatly by how individuals in the patient's social network dealt with cancer ${ }^{49}$. Many patients decline treatment because they have lost a loved one who received solely orthodox cancer treatment and thus see the recommended therapy as ineffective or high-risk. A counselling session with an oncologist may help patients explore differences between their diagnosis and treatment plan compared to that of their family member or friend who died of 
cancer $^{62}$. To provide patients with additional aid, especially around the point of diagnosis, they can be referred to psychosocial support services.

\section{Addressing information-seeking behavior}

The lure of the internet

The patient normally has several sources of information at their disposal, such as physicians, family, friends, peers, and the internet. Illness behavior and therapy choice are governed to a large extent by how patients encounter novel information, judge its trustworthiness, and interpret its content ${ }^{95,96}$. The majority of citizens in Western countries have internet access ( $81 \%$ in USA ${ }^{97}, 89 \%$ in EU ${ }^{98}$ ), and a substantial proportion of those individuals perform searches concerning healthcare issues, especially symptoms and illnesses (USA: $\left.72 \%{ }^{99}\right)$. According to data from $2011,26 \%$ of the US population had followed another person's illness experience in the past 12 months, $16 \%$ is a member of an online patient group ${ }^{99}$. These groups are usually found on social media, which in itself is a prominent source of information for many; in the US alone, $81 \%$ of the population is registered on such a webpage ${ }^{99}$.

In a milieu of profuse and polycentric information production extending into the healthcare sector also, patients not only gravitate towards do-it-yourself internet searches, but are often forced to be what Kelner calls "smart consumers" ${ }^{100}$, orienting themselves among (oftentimes contradictory) healthcare information. These changing sociocultural and behavioral tendencies are also manifest in new patient roles and identities, such as the e-patient: equipped, enabled, empowered, engaged with their own therapeutic process $^{101}$. 


\section{Filter bubbles}

Albeit patients retain a marked need for performing internet searches, the concept and effects of a world wide web based on "relevance" is lessor known to them. Not only are various advertisements tailored to the individual's preferences, but identical searches yield vastly different search results for users ${ }^{102}$. Seeing as most internet users only browse the first page(s) of the search results, the order of presented content is pivotal. Due to the fact that the patient is most likely not aware of the notion of relevance, or does not know how to access the filters governing their query results, they do not perceive what Pariser calls the "filter bubble" around them, creating a self-reinforcing informational environment ${ }^{102}$. Practically speaking, during everyday internet activity, the patient who previously searched for a CAM product (perhaps merely out of curiosity) will see advertisements for similar products (herbs, supplements, crystals, etc.). An individual interested in psychology, for example, who is suddenly diagnosed with an illness, may see more search results promoting "holistic cures" or CAM modalities focused on psychosocial aspects of illness. To the naïve user, these results appear to be the most popular webpages "objectively" the most relevant to their query. Filter bubbles can be considered a manifestation of the confirmation bias, i.e. the tendency to search for, interpret, favor, and recall information that affirms one's prior assumptions ${ }^{103}$.

\section{Echo chambers}

Another manifestation of the confirmation bias is the echo chamber, whereby individuals make conscious (or subconscious) decisions to only subscribe to (sources of) information that are congruent with their own beliefs. For example, a study in 2016 scrutinized 376 million Facebook users' relationship to 900 news portals and found that individuals searched for information that supported their opinion, ignoring conflicting 
portals ${ }^{104}$. The same filtering of information may occur regarding print and other media, as well as interpersonal relationships. These enclosures of information may create homogeneous cognitive stimuli, lead to self-reinforcing loops and informational determinism, which have a strong effect on decision-making in healthcare contexts as well. Regarding therapy choice, the patient will prefer the treatment congruent with their worldview ${ }^{60,100}$, which in turn is largely defined by the individual's informational, sociocultural, and behavioral environment.

Advocate "smart searches"

Due to the present informational landscape, patients will most likely encounter information - both online and offline - that is congruent with their established worldview. Informational determinism can reaffirm convictions that lead to other biases and self-isolating behavior. On the other hand, the abundance of available information and the potential heterogeneity of content may cause mental fatigue and confusion ${ }^{26}$. Notwithstanding, patients wanting to seek out information may have advantages as well; optimally, with more information they can make better-informed decisions, satisfy a need for cognitive closure and feel more secure about treatment choices ${ }^{26}$. The outcomes of such searches rely on many factors, notably media literacy and health literacy.

Advising the patient against seeking information can be detrimental to the doctor-patient relationship as it might convey that the doctor does not trust the patient as a party in decision-making. In the process of informed decision making, the patient obtains information from the clinician and other sources also, then ideally this information is coupled with decision counselling to help patients understand potential risks, benefits, and uncertainties of clinical options ${ }^{105}$. To aid the patient, they can be given tips on 
finding trustworthy information, such as specific, medically reliable webpages and tools. Several, cancerrelated decision aids exist for comprehensively comparing therapies and calculating risk. ${ }^{105}$ Furthermore, patient critical thinking can be boosted by tips like 1) cross-check facts you find on the internet or opinions you hear about, 2 ) be conscious of the keywords you use to search for information (avoid suggestive phrasing, e.g.: disadvantages of X therapy). Additionally, it is important to inform patients about filter bubbles and the potential effects they have on searches. Countermeasures can be suggested, such as: use more than one search engine, use more than one computer and/or download a cache cleaner application to your PC - these will limit the effects of previous searches on new search results.

\section{Addressing the patient's theories of illness causation}

Meaning-making in illness

Illness frequently induces a loss of control ${ }^{106}$, which may trigger a strong need for ascribing meaning to the illness experience in order to increase perceived control ${ }^{2}$. Albeit this may aid disease management or even boost resilience ${ }^{37}$, it can also lead to postponing help-seeking via meaning-making and the normalization of symptoms ${ }^{107}$. In the patient journey, choices of therapy may be significantly influenced by the sociocultural aspects of CAM, namely, distinct worldviews and etiologies providing possible avenues of illness

interpretation $23,29,48$. Patients feeling dissatisfied with their diagnosis, prognosis, or aspects of medical communication (e.g. receiving "insufficient" information on their illness or experiencing a lack of empathy) may be especially prone to searching for novel interpretations regarding their disease and illness experience 62. 
Concepts of health and illness comprise a unified system with other, non-healthcare concepts and are in strong interaction with notions in the social network of the patient ${ }^{108}$. This conceptual framework and related attitudes are significant, as they influence the interpretation of symptoms, health and illness behavior, self-care, help-seeking, appraisal of sources of information, adherence, and coping ${ }^{108-110}$. Lay etiologies usually connote a distilled version of the patient's worldview and patients will tend to select a treatment that is congruent with their theory of illness causation ${ }^{60,111}$.

\section{Listening to lay theories of illness causation}

Creating a shared understanding about the cause and state of the disease, as well as its prognosis and management, is at the crux of doctor-patient communication ${ }^{112}$. The more complete the mutual understanding, the greater the chances of good cooperation. An effective way to enhance understanding and build trust is asking questions, probing the patient's views ${ }^{112}$. Schofield et al. analyzed 314 initial consultations between cancer patients and oncologists; references to CAM were made in 91 of these. Of 156 separate mentions of CAM, the vast majority were initiated by the patient; 101 instances were statements, 11 were questions directed to the patient, and in 44 instances, the doctor completely ignored the topic brought up by the patient ${ }^{113}$. These results illustrate a hesitance in physicians to discuss the topic of CAM and to create room for questions and listening, rather than making statements. This type of communication may not be effective in reaching pivotal issues in illness attribution, CAM use, and interpersonal trust. 


\section{Addressing mutual exclusivity}

\section{Avoid dichotomous thinking}

As discussed earlier, a patient may employ CAM for different purposes (alleviating side-effects, pain management, boosting quality of life, etc.), exhibit varying motivations (acting in congruence with attitudes or preferences, enhancing agency or control, etc.), and use CAM in two very distinct ways (as a complementary therapy or an alternative to biomedicine). These purposes, motivations, and types of use may change throughout the patient journey, as pertinent decisions are made continuously. Furthermore, these factors only become meaningful when weighed against the type of disease, prognosis, and available conventional treatments. CAM use can be dysfunctional if it endangers patient safety, for example, because non-conventional medicine is being employed as an alternative treatment for a life-threatening illness. This situation may occur if the patient and/or the doctor considers biomedicine and non-conventional medicine as mutually exclusive ${ }^{47}$. Such dichotomous thinking limits available treatment options and hinders the patient and physician reaching a consensus if treatment preferences differ.

\section{Aim for integration and cooperation}

Integrative medicine is gaining ground, especially in oncology ${ }^{114}$; albeit, many physicians may feel uncomfortable discussing CAM or ill-equipped in advising patients on this topic (c.f. ${ }^{115}$ ). The level of integration (in theory or practice) can differ greatly among individual physicians, hospitals, and healthcare systems; and logically, integration is not always preferred with every CAM modality/product regarding every disease. Healthcare professionals who employ CAM themselves are generally more likely to discuss or 
recommend CAM to their patients ${ }^{65,115}$. Bearing in mind that mutual exclusivity hinders communication and limits therapeutic options, aiming for some level of integration is a more productive strategy. At the very least, a cancer patient leaning toward the exclusive use of CAM can be reminded that various therapies may be used in tandem. In this context, this is a reasonable claim even for a physician who does not feel comfortable recommending CAM. Another strategy for low-level integration may be to unearth the (psychosocial and clinical) needs of the patient who is leaning towards dysfunctional CAM use and invite the patient to explore alternative (conventional and non-conventional) strategies for meeting those needs. Higher levels of integration can be achieved through cooperation with CAM specialists who are involved in the patient's care. Merely communicating with each other in such a situation, maintaining an unimpeded flow of information, increases patient safety. Finally, integrative medicine is a viable option for oncologists interested in combining non-conventional and conventional treatment methods within their practice.

Leave the door open

If the patient has made the decision to forgo conventional cancer therapy, encourage the patient to stay in contact to maintain ongoing follow-ups and have an opportunity to change their mind about their treatment choice ${ }^{62}$. In a qualitative study, Boon et al. expound several examples of prostate cancer patients feeling rejected and left to their own devices after making a decision to decline one or more biomedical treatments

${ }^{26}$. If all contact is severed with a patient, the chances of them reconsidering their decision decreases and several issues in patient safety may arise.

(insert Panel 1 here - see end of manuscript) 
Panel 1: Recommendations for Communicating with Patients at Risk of Forgoing Conventional Cancer

Treatment

Conclusions

CAM may denote a point of tension in the doctor-patient relationship, as both parties frequently have reservations about discussing non-conventional modality use. Most cancer patients who employ CAM do so in tandem with biomedicine; although less frequent, such usage may pose risks to patient safety via causing adverse interactions or hindering the efficacy of conventional treatment. There is a considerable number of patients who forgo biomedical treatment in order to exclusively employ non-conventional therapies; if this occurs when faced with life-threatening illness, it can be considered dysfunctional CAM use. Inadequate doctor-patient communication may lead to diminished trust and an impeded flow of information. These spur patient non-disclosure regarding CAM use and the autonomous modification of conventional treatment regimens or trajectories. In order to strengthen the doctor-patient relationship and ensure patient safety, further research is needed to explore and expound recommendations for medical communication in this area.

Acknowledgements

The authors would like to thank EFOP-3.6.3-VEKOP-16-2017-00009 for support in publishing this article. 
References

1. Harris P. Prevalence of complementary and alternative medicine (CAM) use by the general population: a systematic review and update. Int J Clin Pract. 2012;66(10):924-939.

2. Arthur K, Belliard J, Hardin S, Knecht K, Chen C, Montgomery S. Practices, Attitudes, and Beliefs associated with Complementary and Alternative Medicine (CAM) use among Cancer Patients. Integr Cancer Ther. 2012;11(3):232-242.

3. Hunt $\mathrm{K}$, Coelho H, Wider B, et al. Complementary and alternative medicine use in England: results from a national survey. Int J Clin Pract. 2010;64(11):1496-1502.

4. Faith J, Thorburn S, Tippens K. Examining CAM use disclosure using the behavioral model of health services use. Complement Ther Med. 2013;21(5):501-508.

5. Bishop F, Lewith G. Who Uses CAM? A Narrative Review of Demographic Characteristics and Health Factors Associated with CAM Use. Evid Based Complement Alternat Med. 2010;7(1):11-28.

6. Verhoef MJ, White MA, Doll R. Cancer patients' expectations of the role of family physicians in communication about complementary therapies. Cancer Prev Control. 1999;3(3):181-187.

7. Wieland L, Manheimer E, Berman B. Development and classification of an operational definition of complementary and alternative medicine for the Cochrane collaboration. Altern Ther Health Med. 2011;17(2):50-59.

8. Ong C, Bodeker G, Grundy C, Burford G, Shein K. WHO Global Atlas of Traditional, Complementary and Alternative Medicine. WHO Centre for Health Development; 2005.

9. Kemppainen LM, Kemppainen TT, Reippainen JA, Salmenniemi ST, Vuolanto PH. Use of complementary and alternative medicine in Europe: Health-related and sociodemographic determinants. Scand J Public Health. 2018;46(4):448-455.

10. Astin J. Why patients use alternative medicine: results of a national study. JAMA. 1998;279:1548-1553. 
11. Thomson P, Jones J, Browne M, Leslie S. Psychosocial factors that predict why people use complementary and alternative medicine and continue with its use: A population based study. Complementary Therapies in Clinical Practice. 2014;20(4):302-310.

12. Horneber M, Bueschel G, Dennert G, Less D, Ritter E, Zwahlen M. How many cancer patients use complementary and alternative medicine: a systematic review and metaanalysis. Integr Cancer Ther. 2012;11(3):187-203.

13. Buettner C, Kroenke C, Phillips R, Davis R, Eisenberg D, Holmes M. Correlates of use of different types of complementary and alternative medicine by breast cancer survivors in the nurses' health study. Breast Cancer Research and Treatment. 2006;100(2):219-227.

14. Chen Z, Gu K, Zheng Y, Zheng W, Lu W, Shu XO. The use of complementary and alternative medicine among Chinese women with breast cancer. J Altern Complement Med.

2008;14(8):1049-1055.

15. Greenlee H, Kwan ML, Ergas IJ, et al. Complementary and alternative therapy use before and after breast cancer diagnosis: the Pathways Study. Breast Cancer Res Treat. 2009;117(3):653665.

16. Pedersen CG, Christensen S, Jensen AB, Zachariae R. Prevalence, socio-demographic and clinical predictors of post-diagnostic utilisation of different types of complementary and alternative medicine (CAM) in a nationwide cohort of Danish women treated for primary breast cancer. Eur J Cancer. 2009;45(18):3172-3181.

17. Shumay DM, Maskarinec G, Gotay CC, Heiby EM, Kakai H. Determinants of the degree of complementary and alternative medicine use among patients with cancer. $J$ Altern Complement Med. 2002;8(5):661-671.

18. Mao JJ, Palmer CS, Healy KE, Desai K, Amsterdam J. Complementary and alternative medicine use among cancer survivors: a population-based study. J Cancer Surviv. 2011;5(1):8-17.

19. McFadden KL, Hernández TD, Ito TA. Attitudes Toward Complementary and Alternative Medicine Influence Its Use. Explore. 2010;6(6):380-388.

20. Verhoef MJ, Rose MS, White M, Balneaves LG. Declining conventional cancer treatment and using complementary and alternative medicine: a problem or a challenge? Curr Oncol. 2008;15(Suppl 2):s101-s106. 
21. Bishop F, Yardley L, Lewith $\mathrm{G}$. Why consumers maintain complementary and alternative medicine use: a qualitative study. J Complement Altern Med. 2010;16(2):175-182.

22. Cant S, Sharma U. Alternative Health Practices and Systems. In: Handbook of Social Studies in Health and Medicine. Albrecht GL, Fitzpatrick R, Scrimshaw SC. (szerk.). Sage Publications; 2000:426-437.

23. Cartwright $\mathrm{T}$, Torr R. Making sense of illness: the experiences of users of complementary medicine. J Health Psychol. 2005;10(4):559-572.

24. Knoll A. The reawakening of complementary and alternative medicine at the turn of the twenty-first century: filling the void in conventional biomedicine. J Contemp Health Law Policy. 2004;20(2):329-366.

25. White $\mathrm{M}$, Verhoef $\mathrm{M}$. Cancer as part of the journey: the role of spirituality in the decision to decline conventional prostate cancer treatment and to use complementary and alternative medicine. Integr Cancer Ther. 2006;5(2):117-122.

26. Boon H, Brown JB, Gavin A, Westlake K. Men with Prostate Cancer: Making Decisions about Complementary/Alternative Medicine. Medical Decision Making. 2003;23(6).

27. Furnham A, Vincent C. Reasons for using CAM. In: Complementary and Alternative Medicine: Challenge and Change. Kelner M, Wellman B, Pescosolido B, Saks M (szerk.). Harwood Academic Publishers; 2000:61-78.

28. Vincent C, Furnham A. Why do patients turn to complementary medicine? An empirical study. Br J Clin Psychol. 1996;35(1):37-48.

29. Siahpush M. Postmodern attitudes about health: a population-based exploratory study. Complementary Therapies in Medicine. 1999;7(3):164-169.

30. Deng G. Integrative cancer care in a US academic cancer centre: the Memorial SloanKettering experience. Current Oncology. 2008;15(2):S68-S71.

31. Stratton T, McGivern-Snofsky J. Toward a sociological understanding of complementary and alternative medicine use. J Altern Complement Med. 2008;14(6):777-783.

32. Bishop F, Yardley L, Lewith G. A systematic review of beliefs involved in the use of complementary and alternative medicine. J Health Psychol. 2007;12(6):851-867. 
33. Singh $\mathrm{H}$, Maskarinec $\mathrm{G}$, Shumay $\mathrm{D}$. Understanding the motivation for conventional and complementary/alternative medicine use among men with prostate cancer. Integrative Cancer Therapies. 2005;4(2):187-194.

34. Scheier M, Carver C. Optimism, coping, and health - assessment and implications of generalized outcome expectancies. Health Psychology. 1985;4(3):219-247.

35. Myers $\mathrm{C}$, Jacobsen $\mathrm{P}$, Huang $\mathrm{Y}$, et al. Familial and perceived risk of breast cancer in relation to use of complementary medicine. Cancer Epidemiology Biomarkers \& Prevention. 2008;17(6):1527-1534.

36. Thompson C. Natural health discourses and the therapeutic production of consumer resistance. The Sociological Quarterly. 2003;44(1):81-107.

37. Thorne S, Paterson B, Russell C, Schultz A. Complementary/alternative medicine in chronic illness as informed self-care decision making. Int J Nurs Stud. 2002;39:671-683.

38. Maskarinec G, Gotay C, Tatsumura Y, Shumay D, Kakai H. Perceived cancer causes: use of complementary and alternative therapy. Cancer Pract. 2001;9(4):183-190.

39. Barrett B, Marchand L, Scheder J, et al. Themes of holism, empowerment, access, and legitimacy define complementary, alternative, and integrative medicine in relation to conventional biomedicine. J Altern Complement Med. 2003;9(6):937-947.

40. Peters G-JY, Crutzen R. Pragmatic nihilism: how a Theory of Nothing can help health psychology progress. Health Psychol Rev. 2017;11(2):103-121.

41. Petrie $K$, Sivertsen B, Hysing $M$, et al. Thoroughly modern worries: The relationship of worries about modernity to reported symptoms, health and medical care utilisation. Journal of Psychosomatic Research. 2001;51:395-401.

42. Furnham A. Are modern health worries, personality and attitudes to science associated with the use of complementary and alternative medicine? British Journal of Health Psychology. 2007;12:229-243.

43. Lahrach Y, Furnham A. Are modern health worries associated with medical conspiracy theories? J Psychosom Res. 2017;99:89-94. 
44. Köteles F, Bárány E, Varsányi P, Bárdos G. Are modern health worries associated with somatosensory amplification, environmental attribution style, and commitment to complementary and alternative medicine? Scandinavian Journal of Psychology. 2012;53:144149.

45. Connor L. Relief, risk and renewal: mixed therapy regimens in an Australian suburb. Soc Sci Med. 2004;59(8):1695-1705.

46. Herzlich $\mathrm{C}$. Modern medicine and the quest for meaning. Illness as a social signifier. In: The Meaning of Illness. Augé M, Herzlich C (szerk.). Harwood Academic Publishers; 1995:151-173.

47. Zörgő S, Olivas Hernández O. Patient Journeys of Nonintegration in Hungary: A Qualitative Study of Possible Reasons for Considering Medical Modalities as Mutually Exclusive. Integrative Cancer Therapies. 2018;17(4):1270-1284.

48. McClean S, Shaw A. From Schism to Continuum? The Problematic Relationship Between Expert and Lay Knowledge - An Exploratory Conceptual Synthesis of Two Qualitative Studies. Qualitative Health Research. 2005;15(6):729-749.

49. Dumalaon-Canaria JA, Hutchinson AD, Prichard I, Wilson C. What causes breast cancer? A systematic review of causal attributions among breast cancer survivors and how these compare to expert-endorsed risk factors. Cancer Causes \& Control : CCC. Published online 2014.

50. Velicer $\mathrm{CM}$, Ulrich $\mathrm{CM}$. Vitamin and mineral supplement use among US adults after cancer diagnosis: a systematic review. J Clin Oncol. 2008;26(4):665-673.

51. Hyodo I, Amano N, Eguchi K, et al. Nationwide Survey on Complementary and Alternative Medicine in Cancer Patients in Japan. JCO. 2005;23(12):2645-2654.

52. Kessel KA, Lettner S, Kessel C, et al. Use of Complementary and Alternative Medicine (CAM) as Part of the Oncological Treatment: Survey about Patients' Attitude towards CAM in a University-Based Oncology Center in Germany. PLOS ONE. 2016;11(11):e0165801.

53. Tascilar M, Jong FA de, Verweij J, Mathijssen RHJ. Complementary and Alternative Medicine During Cancer Treatment: Beyond Innocence. The Oncologist. 2006;11(7):732-741. 
54. Citrin DL, Bloom DL, Grutsch JF, Mortensen SJ, Lis CG. Beliefs and perceptions of women with newly diagnosed breast cancer who refused conventional treatment in favor of alternative therapies. The Oncologist. 2012;17(5):607-612.

55. Arnault D. Cultural Determinants of Help Seeking: A model for research and practice. Res Theory Nurs Pract. 2009;23(4):259-278.

56. Frank A. The Rhetoric of Self-Change: Illness Experience as Narrative. The Sociological Quarterly. 1993;34(1):39-52.

57. Reddy S. Asian Medicine in America: The Ayurvedic Case. Annals of the American Academy of Political and Social Science. 2002;583:97-121.

58. Peuker A, Armiliato M, Kern de Castro E. Causal attribution to cervical cancer. PSICOONCOLOGÍA. 2015;12(2-3):249-257.

59. Faller $\mathrm{H}$, Schilling $\mathrm{S}$, Lang $\mathrm{H}$. Causal attribution and adaptation among lung cancer patients. Journal of Psychosomatic Research. 1995;39(5):619-627.

60. Helman C. Culture, Health and IIIness. Butterworth-Heinemann; 1994.

61. Zörgő S, Peters G, Mkhitaryan S. Attitudes underlying reliance on complementary and alternative medicine. Integrative Cancer Therapies. Integrative Cancer Therapies. 2020;19:114.

62. Verhoef MJ, White MA. Factors in Making the Decision to Forgo Conventional Cancer Treatment. Cancer Practice. 2002;10(4):201-207.

63. Frenkel M, Ben-Arye E. Communicating with Patients about the Use of Complementary and Integrative Medicine in Cancer Care. In: Cohen L, Markman M, eds. Integrative Oncology: Incorporating Complementary Medicine into Conventional Cancer Care. Current Clinical Oncology. Humana Press; 2008:33-46.

64. Frenkel M, Cohen L. Effective Communication About the Use of Complementary and Integrative Medicine in Cancer Care. J Altern Complement Med. 2014;20(1):12-18.

65. Corbin Winslow L, Shapiro H. Physicians want education about complementary and alternative medicine to enhance communication with their patients. Arch Intern Med. 2002;162(10):1176-1181. 
66. Ge J, Fishman J, Vapiwala N, et al. Patient-Physician Communication About Complementary and Alternative Medicine in a Radiation Oncology Setting. Int J Radiat Oncol Biol Phys. 2013;85(1):e1-e6.

67. Tenner L, Hlubocky FJ, Blanke CD, et al. Let's Talk About Those Herbs You Are Taking: Ethical Considerations for Communication With Patients With Cancer About Complementary and Alternative Medicine. JOP. 2019;15(1):44-49.

68. Koehler M, Koehler K, Koenigsmann M, Kreutzmann N, Fischer T, Frommer J. Beyond diagnosis: subjective theories of illness in adult patients with acute myeloid leukemia. Hematology. 2011;16(1):5-13.

69. Morrow GR, Morrell C. Behavioral treatment for the anticipatory nausea and vomiting induced by cancer chemotherapy. N Engl J Med. 1982;307(24):1476-1480.

70. Gajra A, McCall L, Muss HB, et al. The Preference to Receive Chemotherapy and Cancerrelated Outcomes in Older Adults with Breast Cancer CALGB 49907 (Alliance). J Geriatr Oncol. 2018;9(3):221-227.

71. Ruiter RAC, Kessels LTE, Peters G-JY, Kok G. Sixty years of fear appeal research: Current state of the evidence. International Journal of Psychology. 2014;49(2):63-70.

72. Haskard K, DiMatteo M. Promoting treatment adherence. In: Handbook of Communication in Oncology and Palliative Care. Vol Kissane, D., Bultz, B., Finlay, I. (eds). 1 edition. Oxford University Press, USA; 2011.

73. Ernst E. Prevalence of use of complementary/alternative medicine: a systematic review. Bulletin of the World Health Organization. 2000;78(2).

74. Yates J, Mustian K, Morrow G, et al. Prevalence of complementary and alternative medicine use in cancer patients during treatment. Support Care Cancer. 2005;13(10):806-811.

75. Robinson A, McGrail M. Disclosure of CAM use to medical practitioners: a review of qualitative and quantitative studies. Complement Ther Med. 2004;12(2-3):90-98.

76. Eisenberg D, Davis R, Ettner S, et al. Trends in Alternative Medicine Use in the United States, 1990-1997. JAMA. 1998;280(18):1569-1575. 
77. Davis E, Oh B, Butow P, Mullan B, Clarke S. Cancer patient disclosure and patient-doctor communication of complementary and alternative medicine use: a systematic review. Oncologist. 2012;17(11):1475-1481.

78. Soós S, Jeszenői N, Darvas K, Harsányi L. Nem konvencionális gyógymódok használata sebészeti betegek között. Orv Hetil. 2016;157(37):1483-1488.

79. Foley H, Steel A, Cramer H, Wardle J, Adams J. Disclosure of complementary medicine use to medical providers: a systematic review and meta-analysis. Sci Rep. 2019;9.

80. Zörgő S, Purebl G, Zana Á. A Qualitative Study of Culturally Embedded Factors in Complementary and Alternative Medicine Use. BMC Complementary and Alternative Medicine. Published online 2018.

81. Adler S, Fosket J. Disclosing complementary and alternative medicine use in the medical encounter: a qualitative study in women with breast cancer. J Fam Pract. 1999;48(6):453458.

82. Lichstein PR. The Medical Interview. In: Walker HK, Hall WD, Hurst JW, eds. Clinical Methods: The History, Physical, and Laboratory Examinations. 3rd ed. Butterworths; 1990.

83. Kim SS, Kaplowitz S, Johnston MV. The Effects of Physician Empathy on Patient Satisfaction and Compliance: Evaluation \& the Health Professions. 2004;27(3):237-251.

84. Derksen F, Bensing J, Lagro-Janssen A. Effectiveness of empathy in general practice: a systematic review. Br J Gen Pract. 2013;63(606):e76-e84.

85. Jacobs JM, Pensak NA, Sporn NJ, et al. Treatment Satisfaction and Adherence to Oral Chemotherapy in Patients With Cancer. JOP. 2017;13(5):e474-e485.

86. Festinger L. A Theory of Cognitive Dissonance. Stanford University Press; 1962.

87. Gawronski B. Back to the future of dissonance theory: Cognitive consistency as a core motive. Social Cognition. 2012;30(6):652-668.

88. Peter C, Koch T. When Debunking Scientific Myths Fails (and When It Does Not): The Backfire Effect in the Context of Journalistic Coverage and Immediate Judgments as Prevention Strategy. Science Communication. 2016;38(1):3-25. 
89. Wilkes $A$, Leatherbarrow M. Editing episodic memory following the identification of error. The Quarterly Journal of Experimental Psychology. 1988;40(2):361-387.

90. Johnson HM, Seifert CM. Sources of the continued influence effect: When misinformation in memory affects later inferences. Journal of Experimental Psychology: Learning, Memory, and Cognition. 1994;20(6):1420-1436.

91. Omer SB, Amin AB, Limaye RJ. Communicating About Vaccines in a Fact-Resistant World. JAMA Pediatr. 2017;171(10):929-930.

92. Zhou J. Party-Based Political Gridlock Interferes with Rational Dialogue on Key Issues. In: Political Extremism in the United States. Vol p. 79. Doyle E, ed. Greenhaven Publishing LLC; 2018.

93. Lewandowsky S. Beyond Misinformation: Understanding and Coping with the "Post-Truth" Era. Journal of Applied Research in Memory and Cognition. 2017;6:353-369.

94. Nyhan B, Reifler J, Richey S, Freed G. Effectivemessages in vaccine promotion: A randomized trial. Pediatrics. 2014;133:e835-e842.

95. Pereira JL, Koski S, Hanson J, Bruera ED, Mackey JR. Internet usage among women with breast cancer: an exploratory study. Clin Breast Cancer. 2000;1(2):148-155.

96. McMullan M. Patients using the Internet to obtain health information: how this affects the patient-health professional relationship. Patient Educ Couns. 2006;63(1-2):24-28.

97. The US Census Bureau. Computer and Internet Use in the United States in 2016.; 2016. https://census.gov/library/publications/2018/acs/acs-39.html

98. Eurostat. https://ec.europa.eu/eurostat/statisticsexplained/index.php/Digital_economy_and_society_statistics__households_and_individuals\#Internet_access

99. Pew Research Center.; 2011. https://www.pewresearch.org/internet/category/publications/

100. Kelner M, Wellman B. Health care and consumer choice: medical and alternative therapies. Soc Sci Med. 1997;45:203-212.

101. Hoch D, Ferguson T. What I've Learned from E-Patients. PLoS Med. 2005;2(8):e206. 
102. Pariser E. The Filter Bubble: What the Internet Is Hiding from You. Penguin Press; 2011.

103. Nickerson R. Confirmation Bias: A Ubiquitous Phenomenon in Many Guises. Review of General Psychology. 1998;2(2):175-220.

104. Schmidt A, Zollo F, Del Vicario M, et al. Anatomy of news consumption on Facebook. Proc Natl Acad Sci USA. 2017;114(12):3035-3039.

105. Woolf SH, Chan ECY, Harris R, et al. Promoting informed choice: transforming health care to dispense knowledge for decision making. Ann Intern Med. 2005;143(4):293-300.

106. Pierret J. The illness experience: state of knowledge and perspectives for research. Sociology of Health \& IIIness. 2003;25(3):4-22.

107. Robbins J, Kirmayer L. Attributions of common somatic symptoms. Psychological Medicine. 1991;21(4):1029-1045.

108. Furnham A. Explaining health and illness: lay perceptions on current and future health, the causes of illness, and the nature of recovery. Soc Sci Med. 1994;39(5):715-725.

109. Fitzpatrick R. Lay concepts of illness. In: Perspectives in Medical Sociology. Brown, P (szerk.). Waveland Press; 1989:254-267.

110. Good B, Delvecchio Good M. The meaning of symptoms: a cultural hermeneutic model for clinical practice. In: The Relevance of Social Science for Medicine. L. Eisenberg, A. Kleinman (szerk.). D. Reidel Publishing Company; 1980:165-196.

111. Kleinman A. Patients and Healers in the Context of Culture. University of California Press; 1980.

112. Matusitz J, Spear J. Effective Doctor-Patient Communication: An Updated Examination. Social Work in Public Health. 2014;29(3):252-266.

113. Schofield PE, Juraskova I, Butow PN. How oncologists discuss complementary therapy use with their patients: an audio-tape audit. Supportive Care in Cancer. 2003;11(6):348-355.

114. Rossi E, Vita A, Baccetti S, Di Stefano M, Voller F, Zanobini A. Complementary and alternative medicine for cancer patients: results of the EPAAC survey on integrative oncology centres in Europe. Support Care Cancer. 2015;23(6):1795-1806. 
115. Chang KH, Brodie R, Choong MA, Sweeney KJ, Kerin MJ. Complementary and alternative medicine use in oncology: A questionnaire survey of patients and health care professionals. BMC Cancer. 2011;11(1):196. 
WAIT, ASK, LISTEN

-Before talking about treatment options, allow the patient some time to absorb the diagnosis and adjust

-If treatment is offered too soon, the patient may feel pressured to accept and this may have a negative effect on treatment experience and adherence

\section{Listen to the patient's theories of illness causation}

Initiate the conversation about CAM

Ask about reasons for declining treatment
-The patient will gravitate towards treatments that are congruent with their lay etiology -Establish trust through listening; no need to agree or disagree with the patient, just acknowledge their perspective

-Both patients and doctors may be reluctant to discuss CAM use, the treating physician should initiate the conversation and inquire regularly -Patient safety depends on the physician knowing about complementary therapies

-Dig deeper into reasons for declining biomedical treatment; do not dismiss patient rationale -Active listening and the expression of empathy are essential in good communication, which in turn, translates into better adherence

INFORM

Do not employ "scare tactics"

Be clear about side-effects

Offer counseling

Advocate "smart searches"

INTEGRATE AND COOPERATE

Aim for integration

Do not condemn the patient's decisions

Leave the door open

Aim for cooperation
-Avoid statements such as "If you don't accept this therapy, you will be dead within a year." -Appeals to fear are largely ineffective and diminish trust in the doctor-patient relationship

-Inform the patient about the side-effects of conventional treatment, and be ready to discuss them as they arise

-This is crucial, as patients asymptomatic at the beginning of conventional treatment might attribute side-effects to the treatment being "ineffective" or "noxious"

-Many patients decline treatment because they have lost a loved one who received solely orthodox cancer therapy and thus see the recommended treatment as ineffective or high-risk -Offer patients counseling to help them explore the differences between their diagnosis and treatment plan compared to that of their loved one

-In most cases, the patient will perform searches on the internet and try to gather information on treatment options and outcomes

-Encourage seeking information, but warn the patient about filter bubbles and biases; help them to be critical with information they encounter and find trustworthy sources of information

-Regardless of what level of integration a physician is comfortable with, it is productive to avoid dichotomous thinking concerning conventional and non-conventional medicine because it limits therapeutic options and hinders communication -If the patient considers biomedicine and non-conventional medicine as mutually exclusive, reinforce that various therapies may be used in tandem

-If the patient is still deciding, do not condemn CAM, as this strong negative opinion may beget the patient's condemnation toward biomedicine

-While in the process of decision-making or even after a choice has been made, do not condemn the patient's decision or threaten to refuse future treatment; identify and acknowledge the clinical/psychological needs the patient is trying to meet with CAM

-If the patient has made the decision to forgo conventional therapy, encourage the patient to stay in contact to maintain ongoing follow-ups and have an opportunity to change their mind about treatment

-Be open to communicating with CAM providers who are involved in the patient's care; this will boost trust in the doctor-patient relationship -Emphasize that an unimpeded flow of information is necessary for the patient's safety 